\title{
Litharge from Laurion. A medical and metallurgical commodity from
} South Attika

Thilo Rehren, Doris Vanhove, Herman F. Mussche, Mary Oikonomakou

\section{Citer ce document / Cite this document :}

Rehren Thilo, Vanhove Doris, Mussche Herman F., Oikonomakou Mary. Litharge from Laurion. A medical and metallurgical commodity from South Attika. In: L'antiquité classique, Tome 68, 1999. pp. 299-308.

doi : 10.3406/antiq. 1999.1348

http://www.persee.fr/doc/antiq_0770-2817_1999_num_68_1_1348

Document généré le 10/09/2015 


\section{Litharge from Laurion \\ A medical and metallurgical commodity from South Attika}

\section{Introduction}

During the first century AD, both Dioskourides of Anazarbos and Pliny the Elder discuss in some detail the preparation of lithargyros 'silver stone' and spuma argenti 'scum of silver' for medical use of which Pliny in his Naturalis Historia (33, 110) says: «It is used to make an eye-wash and for women's skin to remove ugly scares and spots and as a hair-wash. Its effect is to dry, to soften, to cool, to act as a gentle purge, to fill up cavities caused by ulcers and to soften tumours... it also removes erysipelas and likewise chilblains....» (transl. H. Rackman [Loeb]) Both authors apparently rely on the same source of information. Nevertheless Pliny gives some additional information concerning the metallurgical background of its production $^{1}$. Dioskourides in his De Materia Medica $(\mathrm{V}, 87)$ says about lithargyros that «one is made from sand called molybditis which is roasted until it is totally burned, another from silver, a third from lead. The Attic is excellent, the second is from Spain, followed by those from Dikaiarchia and Sicily» and Pliny (o.c. 33, 106) notes «The same mines also produce the mineral called spuma argenti (scum of silver). Of this there are three kinds, with Greek names meaning respectively golden (chrysitim), silvery (argyritim) and leaden (molybditim)... the Attic kind is the most approved, next the Spanish. The golden scum is obtained from the actual vein, the silvery from silver, and the leaden from smelting the actual lead...» (transl. $H$. Rackham [Loeb]). Despite in both cases the name silver is mentioned, the material is virtually free from silver. It is lead oxide, in English litharge, which forms as a 'waste' during the last stage of silver smelting. As will be shown, it was not at all a waste, but an important commodity in Antiquity. In silver smelting, silver-bearing lead ore $^{2}$ is first smelted to gain metallic lead which collects all the silver present, while the gangue minerals form the slags, or skoriai. The silver content of the lead was usually small, depending on the ore. For the Laurion in South Attika, it is generally assumed to be nearer to one tenth of a percent than to one percent ${ }^{3}$. To gain this silver, the metallic lead is re-melted and oxidised in an open furnace, called

1 For a detailed and interdisciplinary interpretation of these and other chapters on silver metallurgy see PROJEKTGRUPPE Plintus, Silberbergbau und-verhüttung in der Antike, Bochum, 1998.

2 Some silver ores, e.g. in Spain, have insufficient lead mineral. Then, a suitable lead compound has to be added to collect the precious metal. See H.-G. BACHMANN, The archaeometallurgy of silver, in R. FRANCOVICH (ed.), Archeologia delle Attivita Estrattiva $e$ Metallurgiche, Firenze, 1993, p. 563-592, for more details of ancient silver metallurgy.

3 C. Conophagos, Le Laurium antique, Athens, 1980, p. 279; H.-G. BACHMANN, Archäometallurgische Untersuchungen zur antiken Silbergewinnung in Laurion, in Erzmetall, 35 (1982), p. 246-251. 


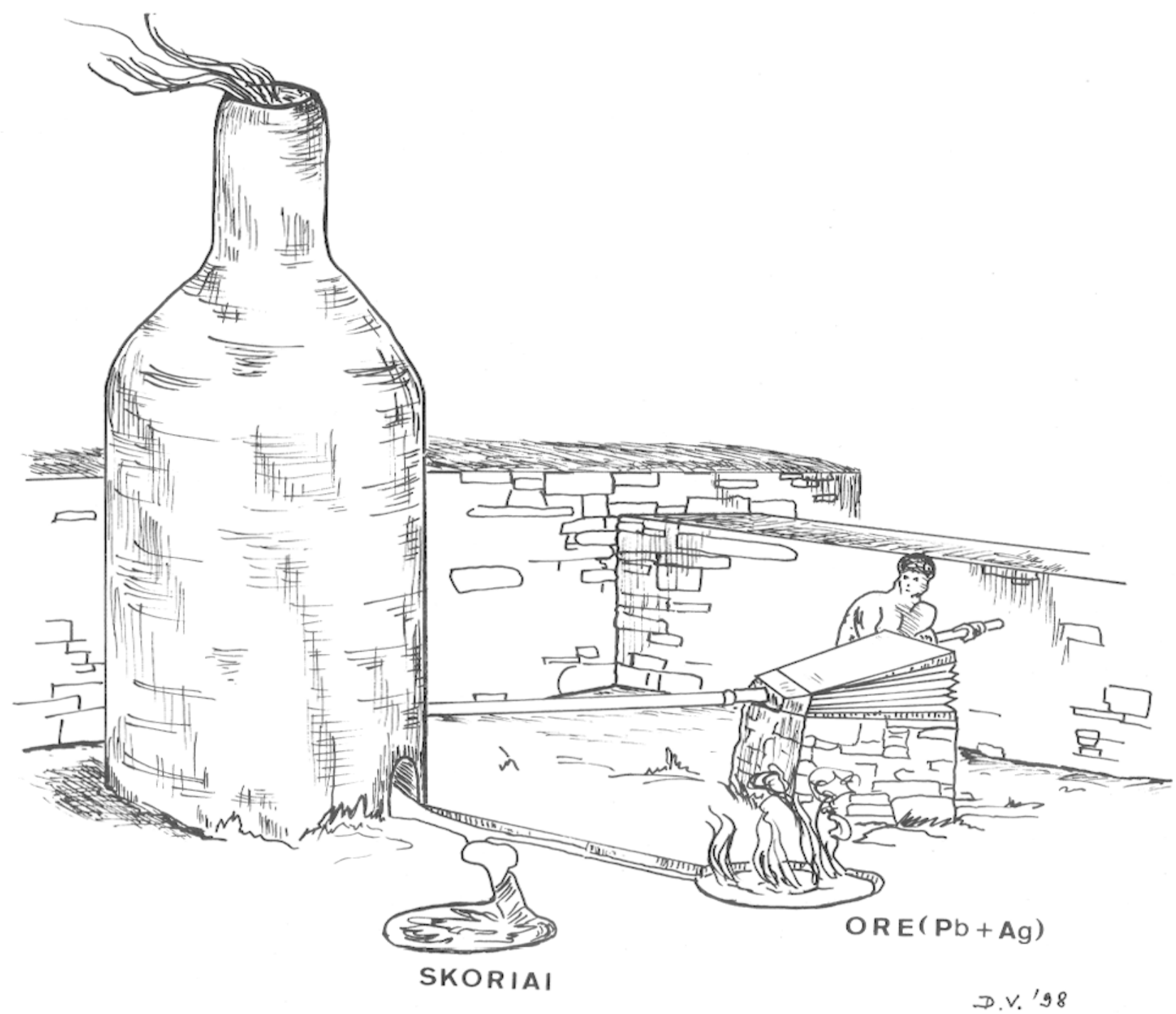

Fig. la. Smelting of silver-bearing lead ore.

cupellation hearth, forming lead oxide or litharge and pure silver (Fig. 1). Therefore, one expects to find substantial quantities of litharge at a silver-producing region, like one finds slags at a metal smelter or a smithy. In the Laurion, however, there is very little litharge in the material record.

The heydays of the Laurion as a major silver producing region were during the fifth and fourth century BC. Mining in the region started, however, already in the early third millennium, and lasted until the sixth century $\mathrm{AD}^{4}$. In his monumental monograph on the metallurgy of this region, $C$. Conophagos calculated the amount of metallic lead smelted during the classical period to about 1.4 million tons, producing $350,000 \mathrm{kgs}$ of silver metal. These figures were based on the quantity of

4 H. Mussche, Thorikos: A Mining Town in Ancient Attika, Gent, 1998, p. 10-16. 




Fig. $1 b(A)$. Cupellation by overflowing of the litharge.

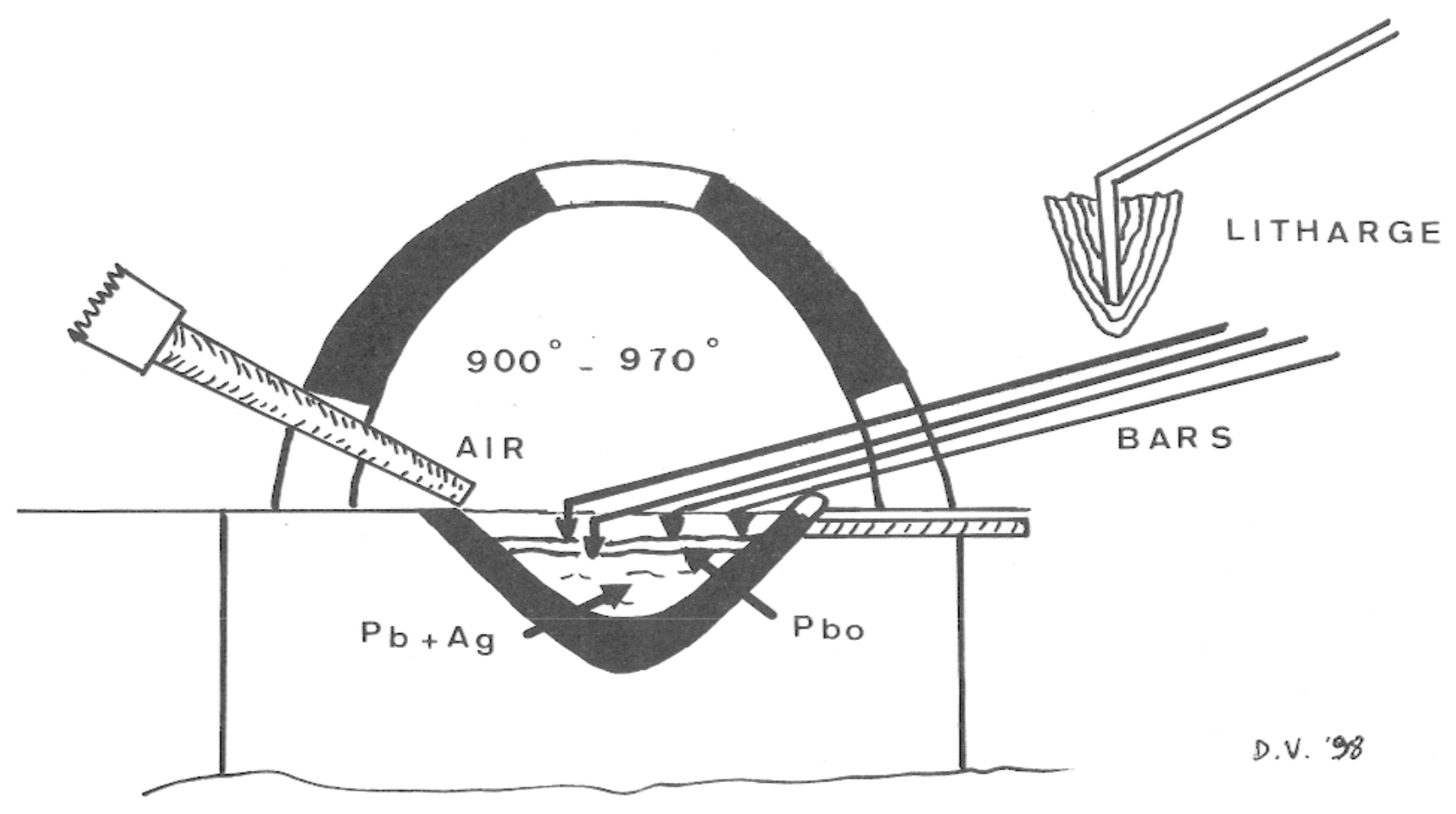

Fig. Ib (B). Cupellation by immersion of bars. 
ancient slag heaps (about 1.5 million tons) and mining debris (well above 10 million tons) as measured during the second half of the 19 th century $\mathrm{AD}^{5}$. The modern exploitation of the region started by processing these materials, which were easily accessible at the surface, already being crushed to a convenient grain size well suitable for modern techniques. Thus, we are faced with an enormous amount of silver being produced in the Laurion during the classical period, and the amount of litharge resulting from the cupellation should be in the same range as the weight of the lead metal, well above one million tons ${ }^{6}$. This is in sharp contrast to any noticeable quantity of litharge in the archaeological record of the Laurion. The few and isolated finds of litharge cakes from the excavations of $C$. Conophagos and $H$. Mussche weight in total not more than a few kilograms. The reworking, by a second smelting, of the litharge to soft or industrial lead may be an explanation; on the other hand even if the Greeks used a lot of industrial lead as in architecture, for anchors, fishing, loom weights, ex-voto's, sheets for packing etc., it is unlikely that all the litharge produced was immediately reworked to industrial lead. In this paper, we try to give several possible explanations for the apparent lack of this litharge.

\section{Litharge in the Laurion}

Until today, there were only two types of litharge known from the Laurion, namely first solid lumps or cakes, and then hollow sticks ${ }^{7}$. Both types of litharge are well known from almost all lead-silver smelting sites in the Old World, and are easily recognised. Why are they so scarce in the Laurion?

During a recent survey and study program, we were able to analyse several sediment samples from several ore washeries in the vicinity of the Belgian Archaeological School in Thorikos. These include two samples of the 'ore deposit' next to the washery no. 1 at Thorikos (samples LTO and LTU, Fig. 2), and several samples from current excavations of the Ephoria $B$ at the slopes of the hill immediately west to the Belgian Archaeological School (LTH2 from the northern slope, property Mexa, Fig. 3).

The sediments from Thorikos were excavated as two distinct heaps, in two rooms adjacent to the washery, containing fragments of mill stones and huge slabs with worked surfaces from grinding material. The sediments look, at a first sight, quite similar to the local soil. On a somewhat closer inspection, however, they are easily distinguished by their significantly higher density (measured densities of these sampels are 5 grams $/ \mathrm{ccm}$, while the local soil density is less than half that value). Also, they have a different texture, sometimes like fine sand, and often show an internal stratification of layers of different grain sizes and hues of brown to red. Sample LTO is from the northern heap, while sample LTU represents the more southern deposit. The total volume of these two deposits is estimated to close to one

5 However, we have to be critical with these number, because some of the modern calculations are inconsistent.

6 While the silver is extracted from the primary lead, thus reducing its weight, the amount of litharge formed is in excess of the metallic lead due to the addition of about one fifth of its weight in oxygen.

7 C. CONOPHAGOS, o.c., p. 313-323. 
$\mathbf{N}$ \

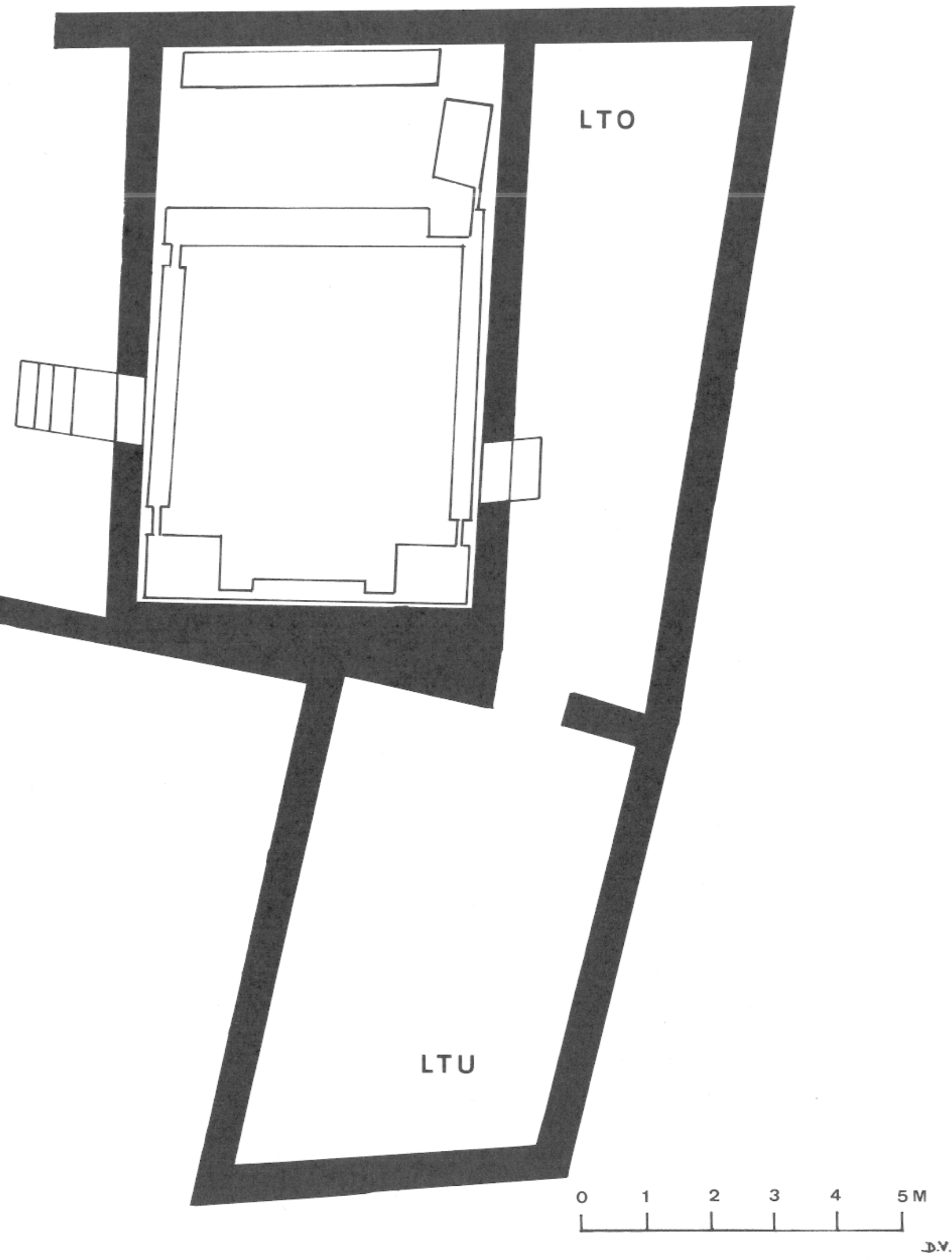

Fig. 2. Thorikos, washery no. 1. 
hundred litres, equalling several hundred kilograms of material. From the stratigraphy of the installation, it is certain that the sediments date to the fourth century $\mathrm{BC}$, and not to a later period of production ${ }^{8}$.

The LTH2 samples originate from a huge, multi-phased washery complex. Here, in two large ore washeries dating to the mid of the fifth-fourth century BC. the fourth century BC we identified lead-rich sediments. They are of a distinct dark purple colour, indicating less soil contamination than in Thorikos. In accordance with this, the measured density of these samples is about $6 \mathrm{grams} / \mathrm{ccm}$, significantly more than the Thorikos material. The most massive occurrence was found at the lower washery A, where it covers one corner of the installation, up to ten centimeters thick, and completely filling in the water channels in that part. No detailed volume measurements were done, but we estimate the amount here to at least 60 liters, equalling about 360 kilograms of material. In the vicinity of the second washery B more uphill, some quantities of the same material were found, probably ten to twenty liters. Minor amounts were also found within the washery installations proper.

According to our analyses, all the samples presented here consist mainly of litharge, ground to a fine powder and mostly weathered, over 2.400 years, to lead carbonate and lead hydro-carbonate. The amount of other components is about 20 percent by weight in the Thorikos material, and about 10 percent by weight in the samples from the property Mexa (Table 1).

Table 1. Chemical composition of sediment samples from washery no. 1 at Thorikos (LTO and LTU) and from the property Mexa (LTH2). The total lead content is given as $\mathrm{PbCO}_{3}$; microscopic investigation showed that not all of the lead oxide is actually transformed into lead carbonate. This and the presence of other elements not listed in the table accounts for most of the difference between the calculated sum of oxides, and 100 percent.

$\mathrm{CaCO} 3$
12,25
11,21
6,05
5,73
7,35

$\mathrm{P} 2 \mathrm{O} 5$
0,18
0,30
0,24
0,19
0,18

$\mathrm{S}$
0,13
0,10
0,09
0,07
0,10

$\begin{array}{ll}\mathrm{Cu} & \mathrm{ZnO} \\ 0,64 & 3,19 \\ 0,09 & 4,20 \\ 0,22 & 0,76 \\ 0,76 & 0,24 \\ 0,78 & 0,48\end{array}$

$\mathrm{PbCO} 3$
62,42
68,45
89,52
82,07
83,35

As
0,24
0,25
0,30
0,05
0,05

$\begin{array}{ll}\text { Sb } & \text { Sum } \\ 0,61 & 93,94 \\ 0,58 & 102,66 \\ 0,71 & 106,90 \\ 0,27 & 94,65 \\ 0,27 & 99,88\end{array}$

Based on a comparision with various kinds of cupellation debris, and after a detailed microscopic and microanalytical study of the samples using thin sections, $\mathrm{X}$ ray diffraction and bulk chemical analyses by ICP-OES, there is no doubt concerning the current, weathered, and the former, original, composition. It is in particular clear that no natural lead ore, galena or cerussite, is present here ${ }^{9}$. Obviously, huge quantities of ground litharge are present at Thorikos and at the property Mexa.

8 For details of the situation of ore washery A2 and its surrounding buildings, see Thorikos I, Rapports préliminaires 1963, Bruxelles, 1968, p. 97-104.

9 Although the basic chemical and mineralogical data of the geological cerussite and the artificial carbonate materials are identical, there are unambigous criteria to distinguish these two, namely the shape and texture of the particles present. Cerussite developed from litharge still preserves the lathy, sometimes wavy shape of the primary litharge crystals, and often still has an uncorroded core of red litharge. Geological cerussite, to contrast, has either its own euhedral crystal faces, or mimics the cubic shape of galena. 




Fig. 3. Property Mexa. 


\section{Interpretation}

This discovery rises some questions, and allows several interpretations. The main question is, why is a deposit of litharge in the ore washery, and why in this condition. Its condition, namely as a fine sand or powder, implies that it was crushed and ground like the ore for which the washeries were originally built. This indicates that the cupellation debris, i.e. the litharge, had some value, enough to justify transport from the cupellation furnaces back to the washeries. Then, time and effort were spent to grind and treat the litharge here. On the other hand, its present occurrence in a relatively significant quantity could indicate that this materials value was limited, making the business secondary.

What, then, was it used for? The treatment in the washeries implies that the use either required a certain grain size and quality of the material, or that it aimed at only a certain fraction of it, which was accessible by washing.

There are at least two uses of litharge in Antiquity we have evidence for. Long known is the addition of fine-grained litharge to produce the famous waterproof and extremely lasting lining of the water-bearing installations in the Laurion, especially cisterns. The demand from this usage, however, was necessarily limited, since the installations where of a lasting nature, and not even all or all parts of them where really done in this way.

The other use we know of is the one mentioned above by Dioskourides and Pliny the Elder, as a basic ingredient for medical preparations. The demand from this for Attic lithargyros will have been significant, considering that it was famous for its superior quality. More important, this demand was independent from the local mining activity, but arose from the daily grieve and illness throughout the Greek, and later Roman, world. When quantities of litharge for the preparations are given, they are usually minai or litrai, indicating that it was used in substantial amounts. Although Dioskourides is speaking of «sand», Pliny (o.c. 33, 108-109) says «In the case of the silvery kind ... the instructions are to break it into pieces the size of a bean and boil it in water in an earthenware pot with the addition of wheat and barley ... Afterwards they grind it in mortars for six days, three times daily washing it, with cold ... and hot water and adding salt ...» (tranls. H. Rackham [Loeb]). Thus, a good deal of the litharge which went into the medical business must have been exported as it formed in the cupellation process, i.e. in solid lumps, and not as a fine-grained, washed powder. Although the local preparation of litharge ointment 'ready for use' can not be excluded, we have yet no evidence for this. Therefore, medical use accounts for the limited occurrence of litharge in the Laurion, but most probably it is not responsible for the litharge found in the washeries.

For this, however, we can offer two possible explanations, both immediately related to the metallurgical activity. The first possibility is the reworking of cupellation debris to gather small droplets of silver and silver-bearing lead which were regularly trapped in cracks and fissures of the cupellation furnaces. Without going into any detail, it may suffice to mention that the silver content of the litharge is in the order of a few hundreds of a percent, which is still one tenth of the original silver content of the ore. This is a typical value for litharge cakes, while the canes of pure litharge have usually less than a tenth of that value. In contrast to the ore, where 
silver and lead are mineralogically related to each other and require high-temperature treatment to separate them, in the litharge most of the silver is present as tiny particles mechanically trapped in the matrix. Due to the silver's physical properties (density, ductility, wetting properties against water) being different from the litharge, it can be gained similar to the way how gold is panned or washed from sand, and the ore from the sterile waste. Therefore, one may assume that the cupellation debris was crushed and washed like ore, to gather the residual silver. This may have occurred immediately after the cupellation, more precisely after each repair or relining of the cupellation furnaces, as it is done even today in modern silver works. As well, however, this may have been the occupation of a later generation. Strabon tells us that in his time (1st century BC/AD) there was a smelting industry based on the reworking of the debris (ekvolades and skoriai) of the ancient activity.

Another possible metallurgical use of the litharge lies in the mineralogical composition of the ore mined in the Laurion. Initial mining, in the Early Bronze Age, may have made use of the rich cementation zone near the surface of the deposit. In classical times, however, it is assumed that predominantly galena, lead sulfide, was mined and smelted ${ }^{10}$. Although the direct smelting of sulfidic lead ore is possible, it would have had profited from previous roasting in order to reduce the sulfur content of the ore. Roasting beds, though, were never found in the Laurion. A similar effect would have been achieved by the addition of lead oxide, which easily reacts with lead sulfide to form metallic lead and gaseous sulfur dioxide. In order to have the reactions taking place, however, the grain size of the reaction partners have to be as similar as possible to allow thorough mixing. Thus, crushing of the litharge cakes would make sense. Furthermore, washing would be necessary to separate the litharge proper from adhering soil and furnace components, which, during smelting, would otherwise eagerly react with the lead oxide, suppressing the slower reaction of lead oxide with lead sulfide. Furthermore, by adding the litharge to the smelting charge, the silver trapped in it would be gained with the metallic lead, making the whole operation more economical.

Whatever is the right answer, the washing of litharge was already done during the fourth century $\mathrm{AD}$, and continued until much later times. Its use may have been the same throughout this time, but it is as well possible that it changed, or developed, over the various exploitation periods. At the present, we can not imagine a way to unambigously determine the reason for this activity; neither in general, nor in the individual case. Far too few technical details of ancient smelting practices at the Laurion are known.

What would have happened with the litharge after washing? In the first case, the finally exhausted litharge would have been dumped together with the other waste from the washeries, more or less sterile mineral sand which became known in later times as plynites. We can only speculate about the exact mineralogical composition of these plynites, now that they are all gone. One single analyses is known with separate figures for lead oxide $(17 \mathrm{wt} \%)$ and lead sulfide $(0.9 \mathrm{wt} \%)$. The total lead content of this sample is too high for the typical plynites, of less then ten weight percent lead, and too low for a typical litharge sediment, of at least $60 \mathrm{wt} \%$ lead. 
Also, the lead oxide measured may have been either geological lead carbonate mineral, cerussite, or primary galena now weathered to lead carbonate. In any case, crushed litharge as a part of the plynites would have gone unnoticed in the modern production.

In the second case, the litharge would mostly have disappeared already in Antiquity. With little economic value in its own, its use would have been dependent on the availability of fresh, primary, ore. A shortage in supply of galena could easily result in the abandoning of a washery specialised in the reworking of litharge, leaving behind large quantities of now worthless material. This seems to be the situation in the property Mexa, where the litharge sediments even contain fragments of roof tiles from the obviously ruined workshop.

Here it is necessary to point out that not all the washeries we have visited so far contain litharge sediments. In many more cases, we identified by visual inspection plynites, i.e., remains of the original ore. These, however, need sampling and subsequent analytical work before any interpretations can be drawn. Clearly, the working of litharge is a significant aspect of the operation of the washeries, not limited to the Thorikos area. But not only more systematic sampling of sediments is necessary, but also, more precise dates for the erection, and the ceasing of operation, of the installations is needed before we can discuss these questions in more detail. In view of their solid construction, and the good condition in which most of the washeries were found, it may be safely assumed that they could have been operative for a century, or re-opened several centuries later for a second period of use. The sediments we find in these washeries now, of course, always represent the very final stages of their operation only.

\section{Conclusion}

The apparent absence of significant quantities of litharge in the Laurion can now be discussed in view of fresh evidence. Firstly, we now know with certainty that significant quantities of litharge were processed on an industrial scale similar to the washing of ore, using the very same installations and, hence, techniques. Furthermore, it was utilised for non-metallurgical purposes, like the preparation of specialised plasters and pharmaca, for which the Attican quality was famous throughout the Roman Empire.

From the large-scale and persisting processing of litharge within the miningmetallurgical complex of the Laurion, secondly, we can conclude that it was either fed into the ancient furnaces, as an additive to enhance the smelting of the primary ore, or that it was dumped together with the regular plynites once the mechanically trapped silver metal was extracted from it. In the first case, the litharge would have gone already in Antiquity, in the latter, unnoticed, with the smelting of the plynites and ekvolades during the years 1865 to $1910 \mathrm{AD}$.

Which one ever of the two possibilities is the correct one, the current findings add an interesting and significant aspect to our understanding of the organisation, and complexity, of the ancient metallurgical operations.

Thilo REHREN (Bochum), Doris VANHOVE (Gent), Herman MUSSCHE (Gent), Mary OIKONOMAKOU (Ephoria B Athens) 